\title{
BMJ Open Individual readiness for transplantation medicine of laypersons and the number of deceased organ donors: a cross- sectional online survey in Japan, South Korea and Taiwan
}

To cite: Asai T, Taniguchi Y, Tsukata Y. Individual readiness for transplantation medicine of laypersons and the number of deceased organ donors: a cross-sectional online survey in Japan, South Korea and Taiwan. BMJ Open 2022;12:e048735. doi:10.1136/ bmjopen-2021-048735

- Prepublication history and additional supplemental material for this paper are available online. To view these files, please visit the journal online (http://dx.doi.org/10.1136/ bmjopen-2021-048735).

Received 06 January 2021 Accepted 05 January 2022

Check for updates

(c) Author(s) (or their employer(s)) 2022. Re-use permitted under CC BY-NC. No commercial re-use. See rights and permissions. Published by BMJ.

Department of Biomedical Ethics and Social Medicine, Graduate School of Medicine, Gifu University, Gifu, Japan

Correspondence to

Tomoko Asai;

to-asai@fujita-hu.ac.jp

\section{ABSTRACT}

Objectives The gap between the numbers of organ donors and recipients is a common problem worldwide. This study was designed to investigate the importance of 'individual readiness', a here introduced novel concept in transplantation medicine and a measure of positive attitudes towards organ donation and transplantation. Design A cross-sectional online survey was used to collect the research data.

Participants The participants were recruited by a Japanese research company and affiliates in South Korea and Taiwan and fulfilled the following criteria: (1) laypersons aged 18-75 years, (2) residents of the countries and (3) understood the questions in their native languages.

Primary outcome measures The survey investigated the interest and attitude of individuals regarding transplantation medicine by asking multiple choice questions. Based on answers concerning attitude, a positive group was identified as willing to be organ donors and recipients, and a non-positive group was identified as unwilling to be donors and recipients. The ratio between the positive and non-positive group, the $\mathrm{P} / \mathrm{N}$ ratio, was introduced as an index of individual readiness.

Results 1500 samples were included in this analysis. Individuals with interest agreed more with statements on organ donation than those without interest, and the P/N ratio per country was compatible with the actual deceased organ donors rate per million population (ADODR).

Conclusions Interest in transplantation medicine was associated with positive attitudes, and positive attitudes were associated with a higher ADODR. These results support that individual readiness is an important determinant for the number of donors. The P/N ratio can be used as an index to assess individual readiness in organ transplantation, at least in countries with minor to moderate popularisation. Further studies of individual readiness using the $\mathrm{P} / \mathrm{N}$ ratio should be undertaken to develop policies and initiatives for increasing organ donations.

\section{INTRODUCTION}

The gap between the number of organ donors and recipients is a common problem globally. This study was designed to reveal the importance of 'individual readiness' to fill this gap.
Strengths and limitations of this study

- The main strength of this study is that it compares the interests and attitudes of laypersons towards transplantation medicine in a simple, objective manner.

- The here introduced concept of 'individual readiness' in transplantation medicine provides a powerful tool for improving the analysis of actual deceased organ donors rate per million population.

- This study was performed in three neighbouring countries in East Asia which, presumably, limited the number of confounding factors.

- The main limitation of the study is the possibility of survey selection bias and, therefore, generalisability issues.

- Limitations of this study include the reliance on selfreported data.

'Readiness' is a state of being prepared for something. ${ }^{1}$ For example, to develop a new hospital division, the fundamental elements of medicine readiness include administration and coordination; healthcare providers; quality improvement; patient safety; policies, procedures and protocols; support services; and equipment, supplies and medications. ${ }^{23}$

This definition appropriately includes materials and services but does not mention the intention of professionals and people's interests and understanding of that community, which are related to the individual readiness examined in this study. Therefore, we divided and defined readiness into two concepts: social readiness and individual readiness.

Social readiness is a state of being prepared for implementing a policy in society. The fundamental elements to develop a new division in a hospital mentioned previously are included in social readiness. In transplantation medicine, social readiness includes organ 
transplant acts, a national organ allocation system, brain death declaration for organ donors, transplant centres, skillful transplant professionals, healthcare insurance systems and other infrastructure. These are all required to perform transplantation medicine adequately and are mainly issues of social authorities, such as governments.

However, individual readiness is an individual state of being prepared for something; in other words, willingness. In medicine, readiness is usually introduced for the cessation of harmful health behaviours, such as smoking and drug abuse. ${ }^{45}$ However, in the present study, we introduce the concept of individual readiness in transplantation medicine as having a positive attitude towards organ donation and transplantation. Adequate individual readiness by the majority of individuals would provide public support for transplantation medicine.

In this study, we conducted an online survey to determine the individual readiness in the three neighbouring countries: Japan, South Korea and Taiwan. These three selected countries have a similar social readiness, such as organ transplant acts, transplant centres and performance of organ transplant as ordinary medical care ${ }^{6-8}$ but exhibit large differences in the numbers of donated organs from the deceased (actual deceased organ donors rate per million population (ADODR); the worldwide index to compare the development of organ donation) (for details see the Methods section). Our working hypothesis was that differences in individual readiness may, at least partially, explain the difference in ADODR among these three countries with similar social readiness.

Many surveys have been conducted in different countries to understand public attitudes towards organ donation and transplantation. ${ }^{9-11}$ However, most surveys were conducted in only a single country without allowing between-country comparisons. In the present study, we surveyed whether people were interested in-and how their attitudes were towards-transplantation medicine, as these are thought to be an expression mode of individual readiness. We also introduced the ratio of positives and non-positives $(\mathrm{P} / \mathrm{N}$ ratio) as a quantitative index of individual readiness. We compared these results with the ADODR to reveal the potential effects of individual readiness on transplantation medicine. Our survey results suggest that the differences in ADODR between the countries Japan, South Korea and Taiwan can be largely explained by differences in individual readiness, which in turn appear to correlate with whether individuals are interested in transplantation medicine.

\section{METHODS}

The cross-sectional web-based survey investigated the participants' interest in organ transplantation and their attitudes towards organ donation and transplantation to assess individual readiness.

We selected three countries for this study-Japan, South Korea and Taiwan-because of the similarity in social readiness, such as organ transplant acts, transplant centres and performance of organ transplant as ordinary medical care and additional reasons:

1. They are all in East Asia and geographically close.

2. The 2015 Health Care Access and Quality Indices for the countries are similar (Japan: 89, South Korea: 86 and Taiwan: 78), indicating their medical care systems are similarly good. ${ }^{12}$

3 . There are no great differences in the per capita incomes. The 2019 nominal Gross Domestic Product (GDP) per capita places Japan at US\$40 246, South Korea at US\$31 $762^{13}$ and Taiwan at US\$25 941. ${ }^{14}$

4. The internet user penetration percentage is similar (Japan: 94\%, South Korea: 96\% and Taiwan: 93\%). ${ }^{15}$

5. The ADODR differs in these countries: Japan: 0.8, South Korea: 8.7 in $2019^{16}$ and Taiwan: 12.3 in $2016 .^{8}$

The questionnaire was administered online in March 2019 to 1500 participants, 500 in each country, comprising equal numbers of men and women, with age segregation. Because the target populations were very large (millions of inhabitants in the right age category per country), according to Cochran's Formula calculation ${ }^{17}$ for achieving a confidence level of $95 \%$, with a margin of error of 5\%, a total of 385 respondents was required. Therefore, we considered our panels of 500 respondents per country as more than large enough. The participants were collected by a Japanese research company and its affiliates in South Korea and Taiwan and fulfilled the following criteria: (1) laypersons aged 18-75 years, (2) residents in the countries and (3) understood the questions in their native languages.

The questionnaire was sent by an online research company (Cross Marketing Inc, Tokyo, Japan) to panel members recruited from the public who are registered with the company. To start, the participants were asked to read an explanatory text on the screen and provide their consent before answering the questionnaire by pushing 'submit'. Only completed questionnaires could be submitted, and all responses were anonymised. The participants were not given monetary compensation for taking part in the study.

We investigated their interest in transplantation medicine because interest could be a basic component of positive attitudes towards organ donation and transplantation. ${ }^{18}$ To assess their interest in transplantation medicine, the participants were asked: 'Are you interested in organ transplantation?'. The answers were yes or no. In this context, 'interest' was used as a general meaning among laypersons, as 'a feeling that causes special attention'. To assess the attitudes towards organ donation, the participants were asked: 'Are you willing to donate your organs after death (brain death/cardiac arrest)?'. The answers were scored on a 5 -point Likert scale: $1=y e s$, $2=$ probablyyes, $3=$ unsure, $4=$ probably no and $5=$ no. To assess the attitudes towards receiving donor organs, the participants were asked: 'Are you willing to receive organs from the deceased if necessary?'. The answers were scored on a 3-point Likert scale: $1=y e s, 2=$ unsure and $3=$ no. 
The respondents who answered yes or probably yes to both questions were categorised as having a positive attitude towards organ donation and transplantation (positive group), while respondents who answered no or probably no or unsure to both questions were categorised as having non-positive attitudes towards organ donation and transplantation (non-positive group). The positive/ non-positive group ratio, the $\mathrm{P} / \mathrm{N}$ ratio, was used as an index of individual readiness. The respondents with combinations of answers that fitted in neither category were not included in the calculation of the $\mathrm{P} / \mathrm{N}$ ratio (and not considered for the estimation of individual readiness), but summaries of their responses can be found in online supplemental tables 1 and 2.

Additionally, we asked the participants if they agreed or disagreed with five positive statements regarding organ donation, such as 'organ donation contributes to society'. The answers were scored on a 5-point Likert scale: 1 =strongly agree, $2=$ =agree, $3=$ =unsure, $4=$ disagree and $5=$ strongly disagree.

The questionnaire also included items to elicit demographic information on age, gender, residence, educational background, occupation, marital status, children and household income. The questionnaires were presented in the participants' native language. They were originally developed in Japanese, then translated into Korean and Taiwanese by experienced translators, and reverse translated into Japanese to verify them for correctness. For the English translation of the questionnaire, see online supplemental file 2A. For the Japanese, Korean and Taiwanese texts of the questions as used in the survey, see online supplemental file 2B.

The responses and the ADODR in the three countries were analysed using descriptive statistics, and the categorical data were analysed using a $\chi^{2}$ test. The median ages were compared using a Kruskal-Wallis test. The $\mathrm{p}$ values $<0.05$ were considered statistically significant. All analyses were performed using IBM SPSS V.26.

\section{Patient and public involvement}

The participants were not involved in the development of the research question, outcome measures, design, recruitment and conduct of this study.

\section{RESULTS}

\section{Characteristics of the respondents}

The respondents' median age was 40 years overall; 46 years in Japan, 41 years in South Korea and 37 years in Taiwan $(p<0.001)$. Although the median age differed between the countries, it aligned with the official reported median age of each country's population from the WHO population data by country. ${ }^{19}$

Of the respondents, $67 \%$ had tertiary education, $59 \%$ were employed, $48 \%$ were married, $48 \%$ had a child/children and $89 \%$ had an annual household income of JPY 2 million (US\$19000) or more. These data are illustrated in table 1 and online supplemental table 3.

\section{Interest in organ transplantation and attitudes towards organ donation and transplantation}

As illustrated in table 2, $732(49 \%)$ respondents out of 1500 were interested in organ transplantation, with the Japanese having the least interest $(39 \%)$ and the highest number of those without interest $(61 \%)$. Taiwan had the largest number of respondents interested in organ transplantation (57\%). The Japanese also had the lowest number of positive responses (including yes and probably yes) to the questions about donating and accepting transplants, and the Taiwanese had the highest. Additionally, the Japanese had the largest number of negative responses (including no and probably no) and unsure responses to the two questions. For a more exhaustive summary of the survey responses, see online supplemental table 4 : tables 2 and 3.

Table 3 shows that respondents with an interest in organ transplantation tended to have positive attitudes. Of the 497 respondents with an interest in organ transplantation, $426(86 \%)$ had positive attitudes. Of the 562 respondents without an interest in organ transplantation, 424 (75\%) had non-positive attitudes. Differences in $\mathrm{P} / \mathrm{N}$ ratios between the countries were compatible with their differences in ADODR.

\section{Agreement with statements on organ donation}

As illustrated in table 4, respondents with an interest were more likely to agree with each statement on organ donation than respondents without an interest. Of the

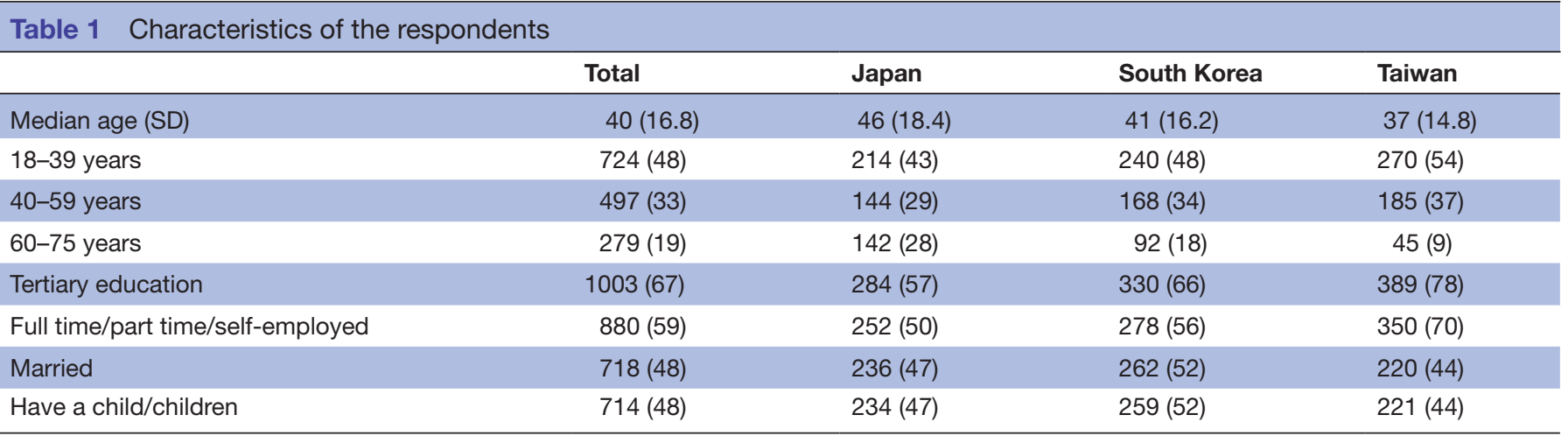

Notes: $\mathrm{n}(\%)$. 
Table 2 Interest in organ transplantation and attitudes towards organ donation and transplantation

\begin{tabular}{|c|c|c|c|c|c|}
\hline & Total & Japan & South Korea & Taiwan & $P$ value \\
\hline \multicolumn{6}{|c|}{ Are you interested in organ transplantation? } \\
\hline Yes & $732(49)$ & $196(39)$ & $249(50)$ & $287(57)$ & $<0.001$ \\
\hline \multicolumn{6}{|c|}{ Are you willing to donate your organs after death (brain death or cardiac arrest)? } \\
\hline Yes/probably yes & $849(57)$ & $208(42)$ & $292(58)$ & $349(70)$ & \multirow[t]{2}{*}{$<0.001$} \\
\hline Unsure & $381(25)$ & $180(36)$ & $118(24)$ & $83(17)$ & \\
\hline \multicolumn{6}{|c|}{ Are you willing to accept transplanted organs from the deceased if necessary? } \\
\hline Yes & $720(48)$ & $129(26)$ & $250(50)$ & $341(68)$ & \multirow[t]{3}{*}{$<0.001$} \\
\hline Unsure & $494(33)$ & $247(49)$ & $147(29)$ & $100(20)$ & \\
\hline No & $286(19)$ & $124(25)$ & $103(21)$ & $59(12)$ & \\
\hline
\end{tabular}

Notes: $\mathrm{n}(\%)$.

respondents with an interest in all three countries, more than $89 \%$ agreed with the following statements: 'Organ donation is to save others in need' and 'Organ donation contributes to society'. Taiwanese respondents that were interested in organ transplantation indicated stronger agreement with all five statements than those in other countries. For a more exhaustive summary of the survey responses, see online supplemental table 5 and table 4 .

\section{DISCUSSION}

This study's findings were that: (1) individuals interested in transplantation medicine tended to have positive attitudes towards organ donation and transplantation and agreed with positive statements on organ donation; and (2) ADODR was compatible with the $\mathrm{P} / \mathrm{N}$ ratio.

As we described in the Methods section, Japan, South Korea and Taiwan have similar social readiness levels for transplantation medicine. We introduced the $\mathrm{P} / \mathrm{N}$ ratio as an index of individual readiness, and the differences in the $\mathrm{P} / \mathrm{N}$ ratio found in our study indicate that individual readiness was different among the three countries. This was compatible with the ADODR differences among the countries.

In her speech to the EU Parliament in 2008, Siiri Oviir, a member of the EU Parliament, emphasised the importance of individual readiness (she used the term 'public readiness') in transplantation medicine. She also mentioned that the most effective way to increase individual readiness would be by improving the knowledge of transplant issues among the public and the media. ${ }^{20} \mathrm{As}$ the media greatly influences the public, emotional news on organ transplantation may attract people's interest. Even in Japan, a low ADODR country, the number of donor registrations in the bone marrow bank increased greatly following a news release on a famous swimming athlete's leukaemia diagnosis. ${ }^{21}$ When people watch the news, their interests increase, and attitudes, such as willingness to be a bone marrow donor, are activated.
Rummel argued that the strength of a person's attitude is based on their interest, and attitudes are activated by interests. ${ }^{18}$ In a book of 'The Theory of Moral Sentiments', Adam Smith remarks that 'there are evidently some principles in his nature that interest him in the fortune of others and render their happiness necessary to him, though he derives nothing from it except the pleasure of seeing it'. ${ }^{22}$ If so, interest in organ transplantation should lead to positive attitudes towards organ donation for patients in need due to human moral sentiment. This was the case in the news story example previously, where interest in bone marrow transplantation increased donor registration.

This idea is also evident in the field of resuscitation. Hallstrom reported that training volunteers in cardiopulmonary resuscitation (CPR) using an automated external defibrillator (AED) and equipping AED increased survival rates in the selected city. ${ }^{23}$ AED equipment in shopping malls can be considered as an amelioration of social readiness. Training volunteers, which is familiarising the use of AED application, would ameliorate individual readiness for out-of-hospital CPR. Thus, CPR is another example that both social and individual readiness are needed for optimal participation and survival rates.

In countries with high ADODR, various social policies are available, such as incentives, first-person authorisation and/or presumed consent to fill the gap between donors and recipients. Whatever policy is used for organ donation and transplantation, individual readiness needs to be included.

Interest in organ transplantation tended to result in positive attitudes, and positive attitudes were positively associated with ADODR. By dividing readiness into two elements, social and individual readiness, this study revealed that individual readiness uniquely affects the number of donors. The $\mathrm{P} / \mathrm{N}$ ratio is a useful index for assessing individual readiness in organ transplantation, at least in countries with minor to moderate popularisation. It is important to continue investigating individual 

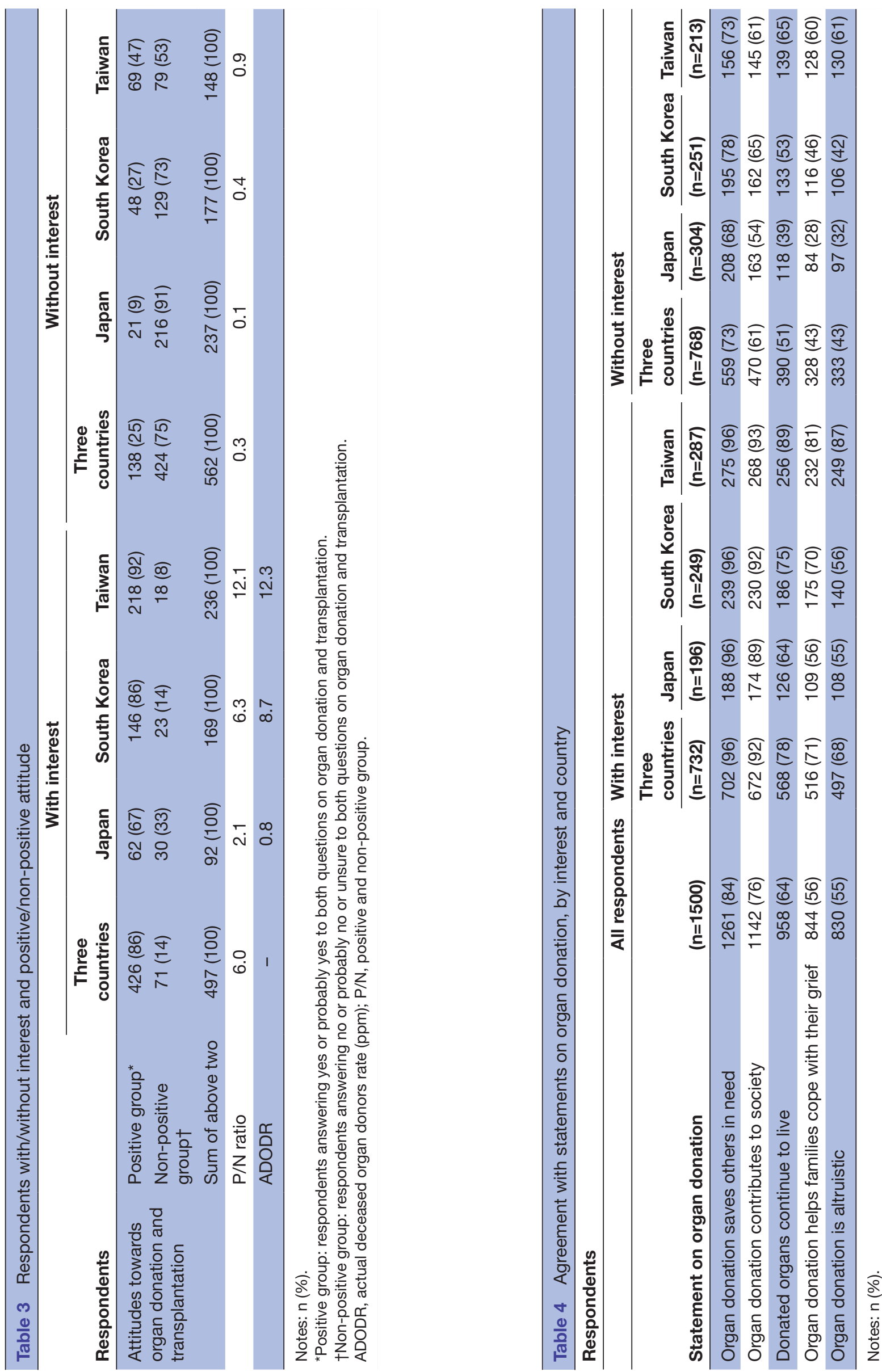
readiness using the $\mathrm{P} / \mathrm{N}$ ratio to evaluate policies and initiatives for increasing organ donations.

Limitations of our study include: (1) Respondents to the online survey were limited to people with online access and a willingness to respond, which may limit the generalisability of the study results for the entire population. (2) The cross-sectional design did not allow us to assess causality. (3) It is unclear whether the positive association of $\mathrm{P} / \mathrm{N}$ ratio with ADODR will also be found in countries with a much higher ADODR than in the three countries that we investigated. (4) Our study relied on self-reported data. (5) Our study relied on the trustworthiness of a single survey company.

\section{CONCLUSION}

This study concludes that interest in transplantation medicine tends to result in positive attitudes that are correlated with - and presumably lead to-a higher ADODR. We introduced the $\mathrm{P} / \mathrm{N}$ ratio as a simple and meaningful index for assessing individual readiness in organ transplantation. It is important to continue to evaluate individual readiness with the $\mathrm{P} / \mathrm{N}$ ratio to evaluate policies and initiatives for increasing organ donations.

Acknowledgements We would like to thank Dr Johannes M Dijkstra of Fujita Health University for his help with the editing of this paper.

Contributors TA designed the study. All authors discussed the preparation of the questionnaire. TA mainly analysed all the data, and YTa and YTs provided advice for the analysis. TA prepared the draft of the manuscript, and all authors contributed to the further edits. All authors read and approved the final manuscript. TA is the guarantor

Funding This study was financially supported by DAIKO FOUNDATION(11051).

Disclaimer The funders had no role in the study design, data collection and analysis, decision to publish or manuscript preparation.

Competing interests None declared.

Patient consent for publication Not applicable.

Ethics approval This study was ethically reviewed and approved by the ethics committee of Gifu University, Japan (Application No. 29-290).

Provenance and peer review Not commissioned; externally peer reviewed.

Data availability statement No data are available. When this study was approved by the ethics committee of Gifu University, due to the sensitivity issues, the collected raw data should not be distributed or used outside of our laboratory.

Supplemental material This content has been supplied by the author(s). It has not been vetted by BMJ Publishing Group Limited (BMJ) and may not have been peer-reviewed. Any opinions or recommendations discussed are solely those of the author(s) and are not endorsed by BMJ. BMJ disclaims all liability and responsibility arising from any reliance placed on the content. Where the content includes any translated material, BMJ does not warrant the accuracy and reliability of the translations (including but not limited to local regulations, clinical guidelines, terminology, drug names and drug dosages), and is not responsible for any error and/or omissions arising from translation and adaptation or otherwise.

Open access This is an open access article distributed in accordance with the Creative Commons Attribution Non Commercial (CC BY-NC 4.0) license, which permits others to distribute, remix, adapt, build upon this work non-commercially, and license their derivative works on different terms, provided the original work is properly cited, appropriate credit is given, any changes made indicated, and the use is non-commercial. See: http://creativecommons.org/licenses/by-nc/4.0/.

ORCID iD

Tomoko Asai http://orcid.org/0000-0002-8978-7625

\section{REFERENCES}

1 Cambridge dictionary. Available: https://dictionary.cambridge.org/ dictionary/english/readiness [Accessed 1 Nov 2020].

2 Owusu-Ansah S, Moore B, Shah MI, et al. Pediatric readiness in emergency medical services systems. Pediatrics2020;145:e20193308.

3 Remick K, Gausche-Hill M, Joseph MM, et al. Pediatric readiness in the emergency department. Pediatrics 2018;142.

4 Brath H, Grabovac I, Schalk H. Prevalence and correlates of smoking and readiness to quit smoking in people living with HIV in Austria and Germany. PLoS One 2016;11:e0150553.

5 Piontek D, Kurktschiev S, Kraus L, et al. "This treatment can really help me" - a longitudinal analysis of treatment readiness and its predictors in patients undergoing alcohol and drug rehabilitation treatment. Alcohol Clin Exp Res 2017;41:1174-81.

6 Soyama A, Eguchi S. The current status and future perspectives of organ donation in Japan: learning from the systems in other countries. Surg Today 2016;46:387-92.

$7 \mathrm{Kim}$ M-im, Oh J, Cho WH, et al. Causes of failure during the management process from identification of brain-dead potential organ donors to actual donation in Korea: a 5-year data analysis (2012-2016). J Korean Med Sci 2018;33:1-10.

8 Wang T-H, Lee P-C, Chiang Y-J. Taiwan's organ donation and transplantation: observation from national registry point of view. $J$ Formos Med Assoc 2017;116:649-51.

9 U.S. Department of Health and Human Services, Health Resources, and Services Administration. National survey of organ donation attitudes and practices, 2019: report of findings, 2019. Available: https://www.organdonor.gov/awareness/materials/psas.html

10 Nordfalk F, Olejaz M, Jensen AMB, et al. From motivation to acceptability: a survey of public attitudes towards organ donation in Denmark. Transplant Res 2016;5:1-8.

11 Othman $\mathrm{MH}$, Dutta A, Kondziella D. Public opinion and legislations related to brain death, circulatory death and organ donation. J Neurol Sci 2020;413:116800.

12 GBD 2015 Healthcare Access and Quality Collaborators, Barber RM, Fullman N, Sorensen RJD. Healthcare access and quality index based on mortality from causes amenable to personal health care in 195 countries and territories, 1990-2015: a novel analysis from the global burden of disease study 2015. Lancet 2017;390:231-66.

13 The World Bank. GDP per capita (current US\$) [online]. Available: https://data.worldbank.org/indicator/NY.GDP.PCAP.CD [Accessed 12 Aug 2020].

14 National Statistics Republic of China (Taiwan). Per Capita GDP (US\$) [online]. Available: https://eng.stat.gov.tw/point.asp?index=1 [Accessed 12 Aug 2020].

15 Internet World Stats. Asia internet use, population statistics data, and Facebook data-June 30, 2020 [online]. Available: https://www. internetworldstats.com/stats3.htm [Accessed 12 Aug 2020].

16 International Registry in Organ Donation and Transplantation. Newsletter 2020 [online]. Available: https://www.irodat.org/img/ database/pdf/Newsletter\%20June\%202020\%20.pdf [Accessed 12 Aug 2020].

17 Statistics how to. Cochran's Sample Size Formula [online]. Available: https://www.statisticshowto.com/probability-and-statistics/findsample-size/ [Accessed 28 Jun 2021].

18 Rummel RJ. Understanding conflict and war: Vol 2:The Conflict Helix: Chapter 6 Intentions, attitudes, and interests [online]. Available: https://www.hawaii.edu/powerkills/NOTE11.HTM [Accessed 1 Nov 2020].

19 World Health Organization. Global Health Observatory data repository: population data by country [online]. Available: https:// apps.who.int/gho/data/view.main.POP2040ALL?lang=en [Accessed 12 Aug 2020].

20 Euro parliament. Organ donation and transplantation: policy actions at EU level (debate) [online], 2008. Available: https://www.europarl. europa.eu/sides/getDoc.do?type=CRE\&reference $=20080421 \&$ secondRef=ITEM-018\&language=EN [Accessed 12 Aug 2020].

21 AERA dot. Increased bone marrow donor registrations following the news release of a famous swimming athlete's leukemia diagnosis [online]. Available: https://dot.asahi.com/wa/2019071100089.html [Accessed 12 Aug 2020].

22 Smith A. The theory of moral sentiments [online]. Available: http:// www.ibiblio.org/ml/libri/s/SmithA_MoralSentiments_p.pdf [Accessed 12 Aug 2020].

23 Hallstrom A, Ornato AP, Weisfeldt M. Public-access defibrillation and survival after out-of-hospital cardiac arrest. $N$ Engl J Med 2015:687-96. 